LCRL-96709

PREPRINT

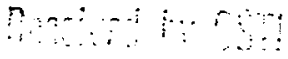

SEP O 91987

\begin{abstract}
Radioactive Fallout in Livermore, CA and Centra]/Northern Alaska from the Chernobyl Nuclear Reactor Accident
\end{abstract}

J. M. Beiriger

R. A. Failor

K. V. Mar'h

This paper was prepared for submittal to 33nd Annual Conference on Bioassay, Analytical and Environmental Radiochemistry

Berkeley, CA

October 6-8; 1987

August 1987

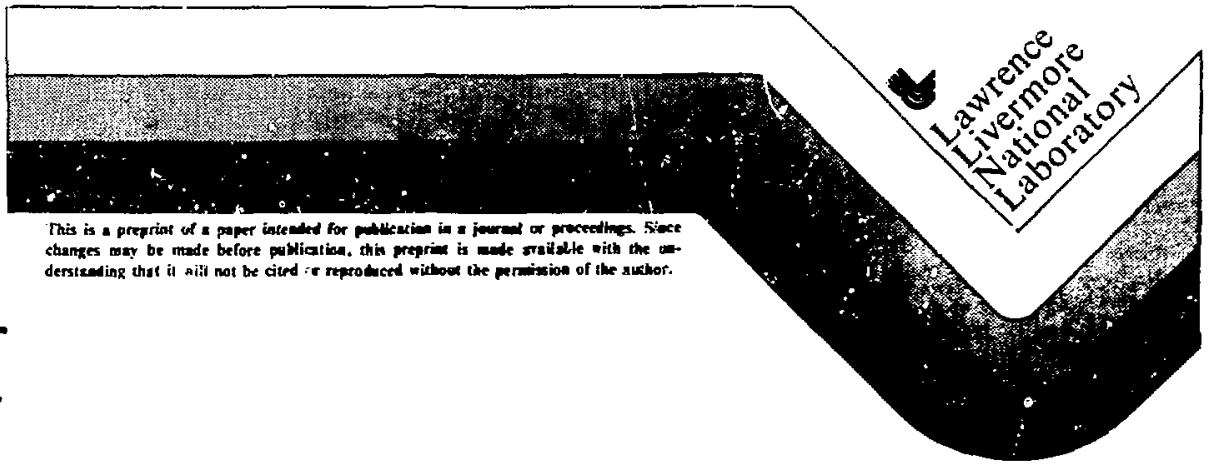




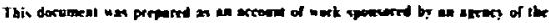

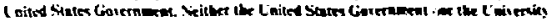

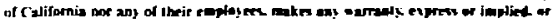

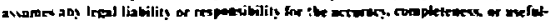

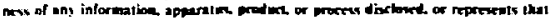

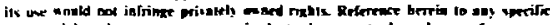

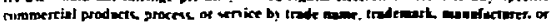

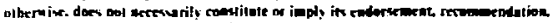

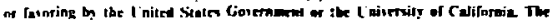

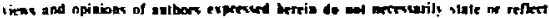

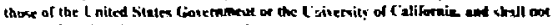

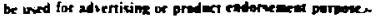




\title{
RADIOACTIVE FALLOUT FROM THE CHERNOBYL NUCLEAR REACTOR ACCIDENT *
}

\author{
J. M. Bciriger, R. A. Failor, K. V. Maish \\ Lawrence Livermore National Laboraiory \\ Li\%ermore, California \\ and G. E. Shaw \\ Geophysical Institutc. University of Ala ika \\ Fairbanks, Alaska
}

UCRL -96709

DE87 014349

When the Chernobyl nuclear-reactor accident was reported on April 29, 1986 it appeared that the radionctive plume would extend over the United States. The prevailing winds were known to be carrying the radioactive plume over Asia and the Pacific Occan toward the western coast of the United States. The modeling efforts of the Atmospheric Relcase Advisory Center (ARAC) predicted that the plume would reach the western Linited States May 5 in the upper atmospherc and Hay 10 near ground level.

At LLNL the Environmental Quality Verification Program (LLNL-EQVP) carries out an extensive environmental surveillance program which includes systematic monitoring of air filtcrs for gamma-emilting radionuclides. Following the Chernobyl accident additional air sampling stations were added. At the Geophysical Institutc at the University of Alaska aerosol samples are routinely collected for chemical determination of the character and levels of air pollution. Following the Chernobyl accident three of the air sampling stations were used to monitor the !evels of radioactive fallout in th:se areas. At two stacions the early filters were changed daily, providing a very gopd time profile of the fallout.

The LLNL-EQVP air samplers consist of $520 \mathrm{~cm}^{-}$Whatman 41 cellulose fiber Cilters through which ambient air is puinped at a rate of 400 to $700 \mathrm{~L} / \mathrm{min}$. The air filtcrs ate at a hcight of $122 \mathrm{~cm}$ above ground level. Under normal conditions twenty-two air samplers operate continuousiy in and around LLNL. The filters are changed weekly and counted monthly. To avoid compromising our normal sampling, two scparate air samplers were instalJed to obtain a much better time profile of the Chernobyl-related activity. As the prevuiling wind is west-southwest in May and June, one sampler was placed on the west perimeter of LLNL and another $1.5 \mathrm{~km}$ south to assure that the activity measurcd was not influenced by LLNL operations. The samplers operated at an average flow rate of $\$ 00$ Limin, and the air filters vere changed thrce times per veek and gamma-counted within hours of removal from the samplers.

In Alaska, air samplers, similar to those described above but with flow rates of 700 to $1600 \mathrm{~L} / \mathrm{min}$, were already in place at Fairbanks, Poker Flat Rocket Range, and Barrow. Under normal conditions the filters are analyzed by neutron activation analysis to determine the chemica' composition of the pollution aerosols. Upon report of the Chernobyl accident the filters were gamma-counted without neutron irradiation to determine the level of radioactive fallout. A sufficjent number of filters were analyzed prior to the arrival of the radioactive plume io provide an upper limit on the normal activity levels. From April 29 until June 15, 1986 the filters were changed on a daily basis. After June 15 the filters were changed biweekly. The Aluskan filters were gamma-counted within days after acquisition.

in particulate samples of normal Livermure Valley air, we routinely detect 7 -Be, 40-K, ind $137-\mathrm{Cs}$ by gamma-ray spectroscopy. The 7-Be and 40-K are naturally occuring isotopes, but low levels of $137-$ Cs occur primarily from long-term global fallout and falluut resuspension. Following the Chernobyl accident, other isotopes, not normally detected, were observed in the air-filter samples. These were 103,106-Ru, 129m,132-Te, 131-I, 134,136-Cs, $140-\mathrm{Ba}, 2 \mathrm{l} 2-\mathrm{Pb}$, and low concentrations of $99-\mathrm{Mo}, 14 \mathrm{l}-\mathrm{Cc}, 1 \mathrm{J0m}-\mathrm{Ag}$, and 125-Sb. All of these isotopes can be attributed to reactor by-products. However, the $212-\mathrm{Pb}$ detected here is attributed to $228-\mathrm{Ra}$ emanations from the soil. The $212-\mathrm{Pb}$ in the air filters is not normally detected because the decay time priur to counting is sufficient to allow the 10.6 hr half-life

\#This work was performed under the 3uspices of the U.S. Department of Energy by Lawrence Livermore National Laboratary under contract No. W-7405-Eng-48.

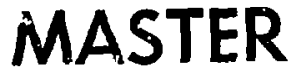


to decay away. As mentioned above, the special air filters were counted within hours of the end of the collection period.

In calculating the concentrations of the isotopes in air, we accounted for the decrease in the air flow rate caused by dust clogging, and for the decay of the short-liver. isotopes on the filter during the collection period. The concentrations were decay corrected to the mid-po:nt of the collection period but not to the time of the Chernobyl accident. This is for two reasons. W/e were interested in the concentrations of the isotopes when they ucre detected in the Livermore area and not at the time of their release from the reactor. Sccondly, the releasc was not instantancous but lasted for many days. Our calculations assumed a constant air concentration during the collecrion period. This assumption is not justified by the data, although lack of further information gives us no alternative. The isoiopic concentrations reforted for the Livermore area are the average of the values for the two special air sampling stations. The concentratica at the two stations generally differed by less than ten pereent.

The maximum concentrations during the May 7-9 Livermore collection was followed by a regular damped oscillatory concentration pattern peaking every six to seven days. Howevcr. our long colicction periods ( 2 to 3 days) make it difficult to determine accurate radionuclide deposition times. Figure 1 show's these trends for 103-Ru, 131-I, and 137-Cs isotope concentrations vs the sumerical day from January 1, 1986 at the end of the collection period. To highlight the similarities of the time profiles of the concentrations. cach isotope was given a different concentration scale and plotted so that the maximum values of May $7-9$ coincide on the scale. The damped oscillation of the concentrations was secn for all the isotopes.

There arc several possible cxplanations for the concentration-time profile measured in the Livermore area. Since the radioactivity rcleasc from the Chernobyl-reactor site lasted for many days it is possible that part of the variation is due to the release paticrn. however. the radioactivity was detected for several weeks afier the last radioactive release so this is probably only a partial explanation. Another explanation is that the air mass containing the radioactive plume passed over the western United States several times before the level of acrivity was below our detection limits. Each time the air mass passed over our area more activity would be detected, at successively lower cancentrations due to continuous deposition and radioactive decay. This would result in the pattern seen in Fig. 1. This explanation has becn proposed by others to explain similiar concentration patterns. It has also been suggested that such an oscillatory pattern is normal for surface deposition from a wide ranging plume. The variety of factors which affect the plume transport rate an produce a striated concentration pattern within the plume. Then as the plume passes over a given area the concentration-time profile of the deposited material will have an oscillatory pattern which will mimic the plume striations ${ }^{3}$.

In Fig. I we also have plotted the decay lines for the three isotopes assuming purely radioactive decay of the maximum activity measured for the time period, May 7-9. Norice chat the 103-Ru and 131-I concentrations appear to show behavior that can be explained by continous deposition and radioactive decay. Howcver, the 137-Cs data shows a much faster removal rate than expected, and implies an accelerated depusition rate. In fact. the disappearanec rate of the 137. Cs is very close to that of the 131.1 . This could be possible if the major species of $131-1$ being transported over the western United Statcs were Csl. The radionctive decay of the iodine would result in the brcak-up of the CsI and enhance the dcposition of the $\mathrm{Cs}^{4}$.

The arrival of the radioactive plume in Alacka coincided with its detcetion in Caljfornia. From April 29 through May 5, 1986 the levels of radionuclides on the daily air filter samples at the three sampling stations in Alaska were below the detcction limits of the systems. Filters which were put in place after 17:20 YDT (Yukon Daylight Time) on May 5 began to show abnormal levels of radioactivity.

In Fig. 2 we show the time profile of the 131-I concentrations masured at one of the three air sampling stations due to the lack of space in this paper. The results from the Poker Flat station are not included because only a $f \mathrm{cw}$ samples were received and the results of these agree with the values measured at the close-by Fairbanks station. OnIv ae 131-I 
data are presented because the majority of the samples were analyzed using NaI detectors and only the $131-1$ peak was relatively free from interference.

The general activity levels measured in Alaska are lower than thosf detected in the Livermore area. This was expected from the path of the radionctive plume. More northernly areas are expected to receive less fallout. It is fortuitous that the Sibcrian High (a normally strong 5pringtime atmospheric teleconnection between Alaska and Central Eurasial had broken down several weeks prior to the Chernobyl accident. Oiherwise this elockwise flow, which is known to bring industrial pollutants from Central Eurasia into the Alastan Arctic causing the "Arctic Haze", would have greatly increased the fallout tevels in Alaska. The daily sample in Alaska presents a better time profile of the early variation in the 131-I concentration than could be obtained by the thrice weekly samples taken in Livermore. As in Fig. 1 we have included lines indicating the effect of radioactive decay on the maximum value obtaincd at each sampling station during the first ten days. Although we see a fairly regular oscillation in the $13 \mid-1$ values during the first sixty days of the sampling, the levels of 131-I do not seem to be decreasing along the decay lines as they did at Livermore. This can be explained by the unusual air flow patterns near the Arctic Cirele. These air flow patterns are known to affect the transport and deposition of particulates in this region and have been studied as explanations of the Arctic air pollution. Full descriptions of these weather patterns are beyond the scope of this report. The unusually high value on July 5 (cay 186) could be due to the influence of anticyclonic air flow during this time period which brought a "heat-wave" and slight precipitation to the area.

The Barrow site :s $805 \mathrm{~km}$ north of the Fairbanks and Poker Flat sites and $265 \mathrm{~km}$ north of the Arctic Circle. Because this is so far north we expected and found lower 131-I concentrations in ais samples. With the breakdown of the Siberian High mentioned above, the radioactive plume would follow the prevailing easterly winds and only a small portion of the activity would reach north of the Arctic Circle. The generat trend of the $131-1$ concentration values shows three major peaks near day 130 (May 10), day 142, and day 155 . Other rallout measurements in the Barrow, Alaska area, by Larsen et al. , show a similar pattern where the maximum detected values ocurred late in May. Unfortunately we have insufficient meterological data to attempt to explain the air flow patterns that could have caused this variation in radioactivity.

\section{REFERENCES}

1. P. H. GUDIKSEN, R, LANGE, "Atmospheric Dispersion Model of Radioactiviey Releases from the Chernobyl Event" to be published in Nature, UCRL-95363 (i986).

2. A. J. THOMAS, I. M MARTIN, Nature, 321 (1986) 817.

3. P. H. GUDIKSEN, Private Communication, Lawrence Livermore National Laboratory, June 1986.

4. J. K. DAWSON, R. G. SOWDEN, Chemical Aspects of Nuctear Reactors, vol. 2 (1963) p. 132.

5. R. I. LARSEN, C. G. SANDERSON, W. RIVERA, M. ZARRICHIELI. "A Compendium of the Environmental Measurements Laboratory's Research Projects Related to the Chernobyl Nuclear Accident", H. L. VOLCHOCK, N. CHIECO (Eds). EML-460, (1986) p. J. 


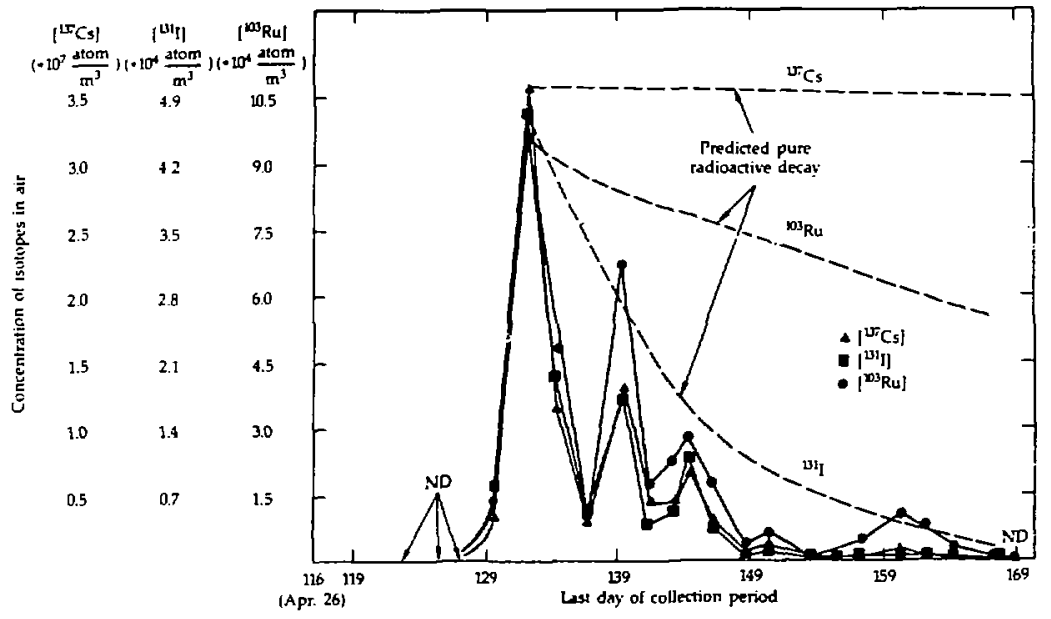

Figure 1. Time proliles of the concentrations of ${ }^{103} \mathrm{Ru},{ }^{131} \mathrm{I}$, and ${ }^{137} \mathrm{Cs}$ in the air in Livermore, Calitomia. To highlight the similarity between the fime profiles of the various isotopes the linear concentration scales of each are adjusted to overlap the maximum concentration points at Day 132 . The units are in atorns $/ \mathrm{m}^{3}$ for comparison of the various isotopes. Also shown is the predicted value for pure radioactive decay of the maximum values detected for each isolope. (ND $=$ nol detected)

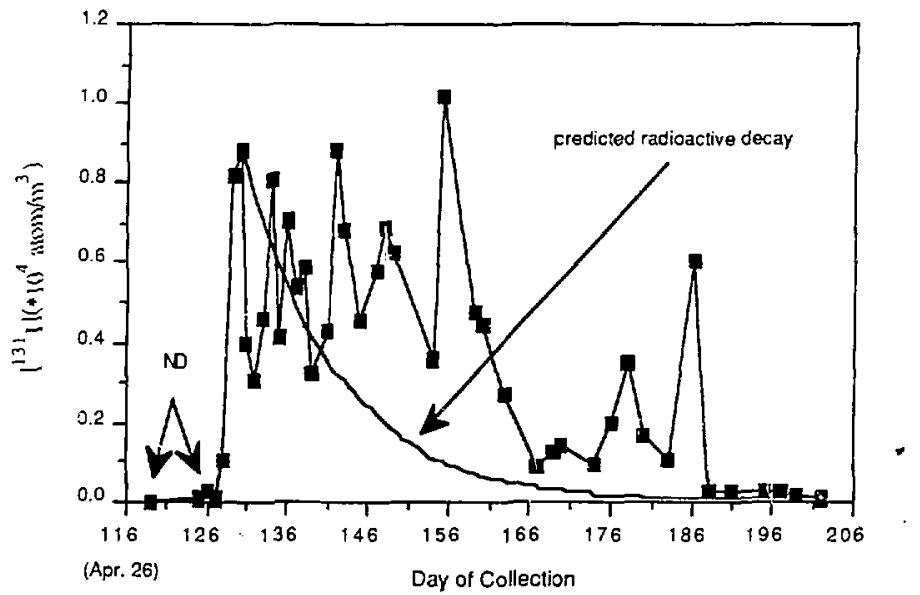

Figure 2. Time profile of the ${ }^{131}$ I concentrations in the air in Fairbanks, Alaska. The linear concentrations are plotted in atoms $/ \mathrm{m}^{3}$ to correspond with the values in Figure 1. Also shown are the predicted values for the pure radioactive decay of the maximum value of the ${ }^{131}$ / detected in the first 10 days after the Chernobyl accident. (ND = not detected) 